\title{
CONSIDERAÇõES GERAIS SOBRE INÍCIO DE CARREIRA
}

\author{
Eliseth Roncáglia* \\ Paola Maresca * \\ Maria Aurora P. Migita *
}

\begin{tabular}{l|c|} 
& $\mathrm{RBEn} / 04$ \\
\hline
\end{tabular}

RONCAGLIA, E., colaboradores - Considerações gerais sobre início do carreira, Rev. Bras. Enf., R.J., 28 : 59-68, 1975

\section{I - INTRODUÇÃO}

O Conselho Internacional de Enfermagem (ICN) define: "É enfermeiro a pessoa que terminou seus estudos básicos de Enfermagem e está capacitado c autorizado a assumir em seu País a responsabilidade dos serviços de Enfermagem que exigem a promoção da saúde, a prevenção da doença e a prestação de assistência aos enfermos"; donde MELO (17) conclui que o recémgraduado em Enfermagem, está apto para as atividades curativas, preventivas e de reabilitação. Assim sendo, surge a seguinte questão:

- O fato do recém-graduado possuir conhecimento para exercer a profissão, implica que tenha condições para assumir as responsabilidades que advém do seu novo "status"?

MELO (17) cita que: "Hoje a educação de qualquer profissional é por essência e por excelência um fator de promoção social, obtendo-se um "status" em cujo âmbito a escola é considerada instrumento de integração, socialização e participação". Como instrumento, a escola deve provocar mudanças exigidas para que, no caso o enfermeiro, adquira seu "status" e conseqüentemente assuma alguns papéis no contexto social do qual passa a fazer parte.

A mudança da situação de estudante para o "status" de enfermeiro, parece colocar o novo profissional em uma situação real, às vezes muito cômoda. Esta premissa, nos levou a tentar conhecer com mais objetividade como o recém-graduado reage diante de seu novo papel.

Reconhecendo que a nossa experiência é ainda limitada pelo pouco tempo de vivência profissional, procuramos conhecer os fatores que podem auxiliar no esclarecimento de algumas dificuldades que o recém-graduado encontra ao iniciar sua carreira. Isto posto, ficamos muito à vontade para esclarecer que nosso objetivo fica limitado à nossa condição de graduada-recente.

* Enfermeiras da Divisão de Reabilitação Profissional de Vergueiro - Hospital das CiíUniversidade de São Paulo. 
RONCAGLIA, E., colaboradores - Considerações gerais sobre início de carreira, Rev. Bras, Enf., R.J., 28 : 59-68, 1975.

II - OBJETIVO

O objetivo deste trabalho, é portanto, demonstrar que o recém-graduado encontra dificuldades ao assumir suas funções frente ao "status" de enfermeiro.

\section{III - DEFINIÇÃO DE TERMOS}

Para facilitar a exposição, foram utilizados alguns termos bastante conhecidos e que foram aqui abordados com a seguinte conotação:

- "Status": "é um conjunto de deveres e direitos que caracterizam a posição de uma pessoa em suas relações com outras." (16)

Assim é inteiramente acertado falar de cada indivíduo como possuindo muitos "status", pois que cada um toma parte na manifestação de numerosos padrões.

O "status" de qualquer indivíduo significa a soma total de todos os "status", que ele ocupa. Representa a posição dele em relação à sociedade total.

- Papel: "representa o aspecto dinâmico do "status". O indivíduo ao efetuar os direitos e deveres que constituem o "status" está desempenhando um papel." (16)

Papel e "status" são inteiramente inseparáveis.

- Função: "conjunto de tarefas ou atribuições exercidas de maneira sistemática." (4)

- Cargo: "é a posição hierárquica desse conjunto de tarefas e atribuições dentro da organização do pessoal da instituição. É a combinação de funções, deveres e responsabilidades, com a autoridade atribuída ao ocupante."

\section{IV - MATERIAL E MÉTODO}

$\mathrm{Na}$ tentativa de obter dados concretos e objetivos, o método escolhido foi 0 formulário, por nos parecer de amplo campo de aplicação, ser mais acessíve] aos pesquisados e por ser preenchido no momento da entrevista. Desta forma. tentamos facilitar a tabulação dos dados

O trabalho foi iniciado com o envio de duas cartas aos Diretores dos Serviços de Enfermagem do Hospital das Clínicas da Faculdade de Medicina da Universidade de São Paulo e Hospital São Paulo, solicitando a permissão para aplicação dos formulários.

Os hospitais acima citados foram escolhidos por possuírem mais de 500 leitos, serem gerais e portanto, com maior diversificação de especialidades.

Foram elaborados dois tipos de formulários, sendo um para recém-graduados, com oito questões (ANEXO I) e outro para enfermeiras responsáveis pelas clínicas com cinco questões (ANEXO II) .

Os enfermeiros recém-graduados, em número de trinta, estavam no seu primeiro emprego como enfermeiros, no decurso do primeiro semestre de trabalho.

As enfermeiras responsáveis pelas clínicas, em número de quinze, estavam há mais de três meses no cargo, supondose que conheciam a situação da clínica e que tivessem recém-graduados sob sua orientação.

A amostragem foi escolhida ao acaso. ou seja, de acordo com o horário de trabalho no dia do preenchimento do formulário, obtendo-se dados nos plantões da manhã e tarde.

Todas as clínicas dos hospitais acima citados foram visitadas, com o objetivo de colher informações nas mais diferentes especialidades.

O formulário para os recém-graduados foi elaborado baseado no objetivo proposto, tentando obter informações com relação ao tempo que ele trabalha como enfermeiro, seu preparo para assumir o cargo, as aptidões que esperava demonstrar, e as aptidões que teve oportunidade de demonstrar até a data da aplicação do formulário.

As questões também tinham como 
objetivo nos fornecer dados sobre a expectativa do recém-graduado em receber fundamentação lógica ou científica sobre as atividades que iria executar, assim como, se havia recebido estes esclarecimentos durante o período que estava trabalhando. Pretendia-se ainda, obter dados sobre o tipo de orientação que o recém-graduado esperava receber e a que the era dada. A última indagação referia-se ao seu preparo atual para assumir o cargo de enfermeiro.

As enfermeiras responsáveis pelas clínicas, responderam ao formulário que teve como objetivo o levantamento de clados sobre as expectativas da enfermeira experiente com relação ao enfermeiro recém-graduado, nos aspectos de: connhecimentos, habilidades, segurança no trabalho, reações demonstradas quando orientado, atividades desenvolvidas para o recém-formado e quais as atividades que poderiam ser delegadas para o enfermeiro menos experiente.

Os formulários, compostos de perguntas abertas e fechadas, deveriam ser respondidos totalmente, tendo-se a oportunicaade de assinalar mais de uma alternativa ras questões fechadas, enquanto que nas abertas, a orientação ou qualquer outro esclarecimento foi padronizado.

Com o intuito de verificar possíveis falhas na compreensão das perguntas feitas, elaboramos um teste piloto. Foram entrevistados onze (11) recémformados e sete (7) enfermeiras responsáveis pelas clínicas. De acordo com as informações recebidas pelos entrevistadores, o formulário aplicado aos recémformados foi reelaborado, seguindo-se no entanto, os princípios básicos das questões anteriores, enquanto que o formulário das enfermeiras responsáveis pelas clínicas não sofreu alteração.

A coleta dos dados foi feita em sete (7) dias, utilizando-se os horários matutino e vespertino, para maior abordagem dos enfermeiros, dispendendo-se em média vinte minutos para cada entrevista.

A reação dos enfermeiros frente ao formulário foi das mais diversas: interesse, admiração, desagrado e até mesmo esquivando-se de responder as questões.

A preocupação freqüentemente verificada por parte dos enfermeiros, era se o formulário teria que ser assinado, entretanto, mediante a negativa da resposta e mostrando que se pretendia manter 0 anonimato da pessoa, houve maior receptividade.

Apesar desses contratempos, a colaboração foi muito boa e conseguimos obter as informações desejadas.

A tabulação (que é uma parte do processo técnico na análise estatística dos dados), foi feita através de contagem manual das questões fechadas e abertas. Das questões abertas foram relacionadas as principais indicações, averiguando-se número e porcentagem.

$\mathrm{O}_{\mathrm{S}}$ resultados foram analisados de acordo com a ordem das questões formuladas.

\section{V - DISCUSSÃO E CONSIDERAÇŐES GERAIS}

Após a tabulação dos dados, passamos a uma análise e discussão das informações obtidas, que relataremos a seguir.

No formulário dos enfermeiros recémgraduados, obtivemos os seguintes dados:

Da população entrevistada, ou seja, dos trinta enfermeiros que colaboraram, $56 \%$ (17) se encontravam trabalhando há 4 e 5 meses; $27 \%$ (8) entre 2 e 3 meses; $10 \%$ (3) entre 0 e 1 mês e $7 \%$ (2) há 6 meses.

Podemos verificar, que os recém-graduados entrevistados estavam dentro da faixa de tempo de trabalho estabelecido, estando a maioria atuando como enfermeiros há 4 e 5 meses. 
RONCAGLIA, E., colaboradores - Considerações gerais sobre início de carreira, Rev. Bras.

Enf., R.J., 28 : 59-68, 1975.

Questão 1: Você acha que estava preparado para assumir o cargo no seu primeiro emprego?

Se a resposta for negativa, por que? $66,7 \%(20)$ se consideravam preparados e $33,3 \%$ (10) responderam negativamente. Destes últimos, $50 \%$ (5) alegaram como causa de não se considerarem preparados, insegurança; $30 \%$ (3) pouca destreza manual; $20 \%$ (2) falta de maior tempo de estágios práticos; $10 \%$ (1) falta de maior fundamentação científica e $10 \%$ (1) desconhecimento do campo de atuação.

Questão 2: Quais as aptidões que você esperava demonstrar quando começou a trabalhar?

Dos trinta recém-graduados que responderam ao formulário, $866 \%$ (26) esperavam demonstrar iniciativa; $73,3 \%$ (22) segurança no desempenho de suas funções; $73,3 \%$ (22) planejamento de cuidados de enfermagem; $70 \%$ (21) conhecimento específico; $60 \%$ (18) liderança; $53,3 \%$ (17) destreza manual e $3,3 \%$ (1) capacidade de trabalhar em equipe.

Estes resultados foram obtidos devido ao fato de serem assinalados mais de uma alternativa.

Questão 3: Você teve oportunidade de demonstrar algumas das aptidões relacionadas na questão 2, no seu emprego atual? Em caso afirmativo, quais?

$80 \%$ (24) dos entrevistados responderam afirmativamente, sendo que destes $83.3 \%$ (20) tíveram oportunidade de demonstrar iniclativa; $54 \%$ (13) destreza manual; $50 \%$ (12) segurança no desempenho de suas funções e $45,8 \%$ (11) demonstraram liderança, planejamento de cuidados e conhecimento especifico.
Questão 4: Você esperava ser esclarecido com fundamentação lógica ou científica sobre as atividades que está executando?

$83,3 \%$ (25) esperavam ser esclarecidos quanto às atividades a serem executadas, enquanto que $12,7 \%$ (5) responderam negativamente.

Questão 5: Você recebeu estes esclarecimentos?

$53,3 \%$ (16) responderam afirmativamente e $46,7 \%$ (14) não receberam esclarecimentos científicos sobre as atividades que iriam realizar.

Questão 6: Você esperava ser orientado para a atividade que iria desenvolver? Por que?

$93,3 \%$ (28) esperavam serem orientados para as atividades desenvolvidas, enquanto $6,7 \%$ (2) responderam negativamente. Dos primeiros, 53,3\% (16), esperavam receber orientação para melhor desempenho de suas funções; $23,3 \%$ (9) por estarem atuando em clínica especializada; $6,6 \%$ (2) por considerarem necessário a orientação a novos funcionários e $3,3 \%$ (1) alega ter tido pouca oportunidade em campo de estágio.

Questão 7: Você recebeu orientação como esperava?

$53,3 \%$ alegaram não haverem recebido orientação como esperavam e $46,7 \%$ responderam afirmativamente.

Questão 8: Atualmente você se considera preparado para assumir o cargo que ocupa? Em caso negativo, por que?

$66,6 \%$ (20) consideram-se preparados para assumirem o cargo atual e $33,4 \%$ (10) responderam negativamente. Dos 
RONCAGLIA, E., colaboradores - Consideraçōes gerais sobre início de carreira, Rev. Bras.

Enf., R.J., 28 : 59-68, 1975.

últimos $60 \%$ (6) alegaram falta de segurança; $20 \%$ (2) falta de maior fundamentação científica; $20 \%$ (2) inexperiência e $10 \%$ (1) desconhecimento de rotinas.

No formulário aplicado às enfermeiras responsáveis pelas clínicas, as informações obtidas foram as seguintes:

Questão 1: Que conhecimentos, habilidades e atitudes você espera encontrar no recém-graduado?

Das quinze enfermeiras pesquisadas, $100 \%$ (15) esperam que o recém-graduado tenha conhecimento científico; $60 \%$ (9) destreza manual e $40 \%$ (6) atitudes Das atitudes que se esperava encontrar. relacionamos as seguintes: boas relações humanas, responsabilidade, ética observação, interesse e iniciativa

Questão 2: Quando você dá orientação, quais das atitudes abaixo relacionadas você prefere que a pessoa orientada assuma:

$40 \%$ (6) responderam que gostariam que o recém-graduado demonstrasse ter objeções quando as tivesse; $26,7 \%$ (4) que argumentasse e demonstrasse ter objeções quando as tivesse e $6,6 \%$ (1) que recebesse orientação sem objeções

Questão 3: Quais as atividades educativas que você programa e desenvolve para a enfermeira recém-graduada?

$66,6 \%$ (10) orientam quanto às rotinas e planta física da clínica; $53,7 \%$ (8) não desenvolvem nenhum programa; $26,6 \%$ (4) dão orientação quanto a aparelhos específicos; $26,6 \%$ (4) elaboram programa quanto a planejamento e cuidado de enfermagem; $6,6 \%$ (1) acompanhamento com veterana e $6,6 \%$ (1) esclarece quan- to ao relacionamento da Enfermagem com os serviços afins

Questão 4: Por quanto tempo você espera que o recém-formado solicite orientação?

$60 \%$ (9) esperam que o recém-graduado solicite orientação de 60 a 90 dias; $20 \%$ (3) entre 0 e 30 dias e $20 \%$ (3) de 180 a 1 ano.

Questão 5: Quais das suas atividades você poderia dividir com 0 enfermeiro recém-graduado? (Tabela I)

96,6\% (14) delegam o planejamento. de cuidado a pacientes graves e cuidados a pacientes graves; $40 \%$ (6) atividades burocráticas; $33,3 \%$ (5) orientação aos funcionários e $6,6 \%$ (1) montagem e conservação de aparelhos.

Com a análise dos dados obtidos, verificamos que parece não existir grande concordância de expectativas tanto do recém-graduado quanto ao que é esperado dele.

Notamos que em geral, os recém-graduados esperavam demonstrar (em ordem decrescente): iniciativa, segurança no desempenho de suas funções, planejamento de cuidados de enfermagem, liderança e conhecimento específico, no: entanto, as expectativas das responsáveis pelas clínicas onde os mesmos estavam atuando, gostariam que fosse demonstrado conhecimento científico, destreza manual e atitudes. Nas atitudes. as consideradas mais importantes foram: boas relações humanas, responsabilidade, ética, observação, interesse e iniciativa. Podemos notar, que as expectativas não coincidem, parecendo não haver uma perfelta interação no trabalho destes profissionais.

Observamos ainda, que as aptidões demonstradas pelo recém-graduado entram em conflito com as próprias expectativas, e, segundo HOPP (9) "sempre que" 
RONCAGLIA, E., colaboradores - Considerações gerais sobre início de carreira, Rev. Bras.

Enf., R.J., 28 : 59-68, 1975.

as necessidades e aspirações são esquecidas, as pessoas tendem a desenvolver uma atitude de resistência e antagonismo". Se isto ocorre e o recém-graduado não tem oportunidade de demonstrar suas capacidades e desenvolver suas potencialidades, parece-nos difícil, haver integração e o desenvolvimento de um bom trabalho. Se o ambiente oferecido ao recém-graduado, não proporciona condições para que cultive suas capacidades e aprimore aptidões latentes, possivelmente o dia a dia condicionará a uma seqüência de atividades que poderão concorrer para torná-lo um indidívuo sem estímulo para a resolução dos problemas que surgirem.

De acordo com LEVINSON (15), "a organização também contribui para o crescimento das pessoas através das demandas que lhes impõe e que as estimulam a novo aprendizado. Mudanças técnicas, novos problemas a serem enfrentados estimulam o crescimento da pessoa. O crescimento da pessoa contribui para o caráter da organização.

Um homem pode identificar-se com seu superior, mas também traz alguma coisa de sua própria personalidade para a organização. A medida que ele se torna mais experiente, outros vão identificar-se com ele. Ele deixa alguma coisa de si próprio na organização, contribuindo, dessa forma, para o seu crescimento".

Os dados nos mostram que $83,3 \%$ dos recém-graduados esperavam receber orientação para as atividades que iriam executar e que $46,7 \%$ não receberam estes esclarecimentos, parecendo não haver estímulo para novo aprendizado. Se não houve oportunidade para novo aprendizado, pode-se pensar que não houve contribuição para o que LEVINSON afirma e conseqüentemente não ofereceu auxílio para o desenvolvimento das pessoas.

$40 \%$ das enfermeiras responsáveis pelas clínicas, ao darem orientações, gostariam que os recém-graduados demons- trassem ter objeções quando as possuíssem, mas pelos resultados obtidos, o número de orientações é bastante reduzido, o que parece ser uma contradição, pois é necessário oferecer oportunidades para que algumas objeções surjam.

Dos resultados obtidos pelo formulário, observamos que $60 \%$ das enfermeiras responsáveis pelas clínicas esperam que o recém-graduado solicite orientação entre 60 e 90 dias, sendo que a partir deste período já poderia ser considerado apto para assumir as responsabilidades que o "status" lhe impõe. O aprendizado em relação à planta física não parece ser difícil, enquanto que as atividades burocráticas da clínica, parecem ser de aspecto repetitivo, havendo ainda manuais de rotinas para a orientação aos interessados. Se a maioria das orientações dadas, restringem-se à planta física e atividades burocráticas, o período para o qual o recém-graduado poderia ser considerado apto, parece ser muito extenso. Verificamos, também, que das enfermeiras responsáveis pelas clínicas, $66,6 \%$ (10) orientam quanto a rotinas e planta física; $53,7 \%$ (8) não desenvolvem nenhum programa e $26,6 \%$ (4) possuem atividades planejadas a serem desenvolvidas com o recém-graduado.

Analisando os dados, percebemos que houve unanimidade de resposttas em relação a divisão de trabalho com o recém-graduado, que seriam: planejamento e cuidados a pacientes graves, ficando, de uma maneira geral, as atividades burocráticas e orientação a funcionários, para as enfermeiras mais experientes. Segundo CARVALHO (3), "a manutenção de enfermeiro em uma unidade de enfermagem dispendendo $85 \%$ de seu tempo em atividades burocráticas ou mesmo domésticas e anti-econômicas para o hospital, causa frustação ao próprio enfermeiro e confunde as Escolas de Enfermagem.

Cabe ao enfermeiro como elemento mais categorizado da equipe de enfer- 
RONCAGLIA, E., colaboradores - Consideraçōes gerais sobre início de carreira, Rev. Bras. Enf., R.J., 28 : 59-68, 1975.

magem a tomada de decisões, o julgamento de situações, a orientação de seu pessoal e o controle de todas as atividades de sua unidade, isto é, cabe a ele administrar a unidade.

As tarefas ditas administrativas, porém. variam em complexidade e importância. Algumas, que hoje fazem parte das atribuições específicas do enfermeiro-chefe, podem perfeitamente, a nosso ver, passar a serem desempenhadas por outro elemento, o que resultaria $\mathrm{em}$ aumento do tempo de que aqueles dispõem atualmente para se dedicarem à assistência do paciente. $\mathrm{O}$ probiema nos parece ser de atribuições ou de distribuição de tarefas".

Completando esta afirmativa, HORTA (13) refere que: "as enfermeiras em cargos de chefia delegam ao pessoal auxiliar, sem orientação e supervisão adequacia, a função de observar e atender às necessidades dos pacientes, daí resultancio baixo nível de identificação de problemas, e por conseguinte, baixo nível de cuidados de enfermagem".

Verificamos que $96,6 \%$ das enfermeiras responsáveis pelas clínicas esperam que o recém-graduado planeje e dê cuidado de enfermagem a pacientes graves; $66,6 \%$ orientam quanto às rotinas e $26,6 \%$ elaboram programa quanto a planejamento e cuidado de enfermagem. Pelos dados acima, notamos que parece não existir coincidência quanto à orientação dada ao recém-graduado e ao que se espera dele. Existe quase unanimidade $(96,6 \%)$ de enfermeiras que delegam ao recém-graduado, planejamento e cuidado de enfermagem a pacientes graves, no entanto, pelo exposto anteriormente, a orientação é dirigida em relação à planta física e atividades burocráticas. Se não há orientação sobre o planejamento e os cuidados prestados a pacientes graves na unidade onde 0 recém-graduado atua, parece incoerente delegar estas atividades quando a orientaçāo dada refere-se a outros aspectos.
Nestas condições, .analisando os dados obtidos no formulário do recém-graduado, observamos que $66,6 \%$ se consideram preparados para assumirem o cargo que atualmente ocupam. As atividades que estão sendo executadas pelo recém-graduado e para as quais já havia sido orientado na Escola, deveriam ser complementadas nas unidades de trabalho, mas notamos que as orientações dadas são de aspectos burocráticos, o que nos parece ser incongruente.

Observamos que o recém-graduado, no seu primeiro emprego, tenta demonstrar suas capacidades, mas nem sempre a instituição oferece condições propícias para o desenvolvimento e aprimoramento das aptidões ainda latentes, pela orientação insuficiente.

É nesta fase de adaptação que é importante o apoio, compreensão e orientação planejada por parte de enfermeiros experientes. Sabe-se que as enfermeiras responsáveis pelas clínicas possuem uma vivência inigualável, adquirida no decurso de sua vida profissional e que tiveram a oportunidade de amadurecer e arquivar dentro de si, um material precioso, ou seja, experiência.

Por outro lado, temos o recém-graduado, repleto de novas técnicas e conhecimentos recentes, mas sem experiência suficiente para aplicá-los devidamente e assim tentar vencer os obstáculos que podem surgir no início da carreira. Portanto, estamos diante de dois grupos distintos, ambos com alguma bagagem científica a oferecer, teórica ou prática.

As palavras de LEVINSON (14) auxiliam a esclarecer, o que estamos dizendo: "a reciprocidade estimula o crescimento psicológico de várias formas. Quando a organização está funcionando bem e a pessoa sente-se como sua parte integrante, ela está se identificando com seu superior. Isto significa que ela está tomando algumas de suas habilidades, experiências, pontos de vista e conheci- 
RONCAGLIA, E., colaboradores - Considerações gerais sobre início de carreira, Rev. Bras.

Enf., R.J., 28 : 59-68, 1975.

mento como parte dela mesma. Através de múltiplas identificações de sua reorganização para adptá-las à sua estrutura de personalidade, a pessoa torna-se mais qualificada e ocupacionalmente madura”. Tais palavras, vindas de pessoa tão capacitada, nos coloca muito à vontade para afirmar que a partir do momento em que os enfermeiros responsáveis pelas clínicas e os recém-graduados aceitarem a reciprocidade como algo que vai colaborar para o crescimento da instituição e conseguirem fazer com que haja concordância de expectativas, teremos um grupo coeso e integrado, com condições de oferecer um bom rendimento no trabalho.

Neste nosso despretensioso trabalho, pudemos constatar que se há reciprocidade, ela não foi demonstrada ao responderem as questões formuladas. Recorremos, portanto, a CANTANHEDE (2), com ums referência que se faz oportuna: "o estágio, o aperfeiçoamento e a rea- daptação são fases de um mesmo problema que é o da formação profissional".

\section{VI - CONCLUSÃO}

A nossa tentativa neste trabalho, foi de alertar os enfermeiros experientes sobre as dificuldades encontradas pelo recém-graduado, suas expectativas e aspirações, para que fosse estudada alguma forma de integração que auxiliasse durante a mudança do "status" de estudante para o de enfermeiro.

Este trabalho, no entanto, não é conclusivo, mas tem a intenção de alertar os profissionais para um estudo mais detalhado dos problemas encontrados pelo recém-graduado, dando margem a que $o$ assunto seja pesquisado profundamente, tanto pelos responsáveis pela formação profissional do enfermeiro, quanto por aqueles que os recebem ao se graduarem.

\section{REFERENCIAS BIBLIOGRAFICAS}

1. BERNARD \& JENSEN. - Sociology, 5, 7. ${ }^{8}$ ed., Saint Louis, Mosby, 1958.

2. CANTANHEDE, C. - Curso de organização do trabalho, 8. $^{\mathrm{a}}$ ed., São Paulo, Ed. Atlas, 1968.

3. CARVAlHO, A. C. - Plano de cuidados de enfermagem como uma das funções do enfermeiro-chefe. Revista da Fscola de Enfermagem da U.S.P. 2 (1) : 108-117, mar, 1968.

4. ChiAveñto, I. - Administração de pessoal (I.) Curso de Administração Hospitalar para graduados, São Paulo, 1971.

5. DI LASCIO, C. M. D. S. - "Integração do recém-graduado na vida profissional", Sub-tema I. In Congresso Brasileiro de Enfemagem iXXII, são Paulo, 1970.

6. DUTRA, V. O. - Preparo em serviço para integração do recém-gradua- do na vida profissional. Revista Brasileira de Enfermagem. Rio de Janeiro, 23 (3, 4, 5, 6): 75-79, jul/ dez, 1970.

7. ETZIONI, A. - Orga nizações modernas, 1. ${ }^{2}$ ed., São Paulo, Ed. da Universidade de S. Paulo, p. 105-224, 1974.

8. HENRY, W. E. - O dirigente empresarial: a psicodinâmica de um papel social. Trad. Fernando C. P. Motta, são Paulo, Fundação Getúlio Vargas, 1970. Original inglês: The R.usiness executive the psycho-dynamics of Social Role.

9. HOPP, M. I. R. - A organizaçāo e as funções do administrador. São Paulo, Fundação Getúlio Vargas, 1973.

10. HOR'A, W. A. - Aspectos do conforto do paciente em hospitais. Revista Brasileira de Enfermagem. 17 (34) : :114-118, 1964. 
RONCAGLIA, E., colaboradores - Considerações gerais sobre início de carreira, Rev. Bras Enf., R.J., 28 : 59-ษ8, 1975.

11. IORTA, W. A. - O ensino dos instrumentos básicos de enfermagem. Revista Brasileira de Enfermagem. 24 (3-4): 159-169, 1971.

12. HORTA, W. A. - A cbservação sistematizada como base para diagnóstico de enfermagem. Revista Brasileira de Enfermagem. 24 (5) : 46$53,1.971$.

13. HORTA, W. A. - A observação sistematizada na identificação dos problemas de Enfermagem em seus aspectos físicos. Revista Brasileira de Enfermagem. $2 \boldsymbol{r}$ (2): 214-219, 1974.

14. KLEIN, J. - O trabalho de grupo. 1. ${ }^{\mathrm{a}}$ ed., Rio de Janeiro, Zahar Ed., 1965.

15. LEVINSON, H. - Reciprocidade: o relacionamento homem-organização, trad. Fernando C. P. Motta, São Paulo, Fundação Getủlio Vargas.

16. LINTON, R. - O homem. Trad. de
Lavínia Vilela, 5. ed., São Paulo, Martins editora, $196 \overline{.}$.

17. MELO, J. - Introdução do recém-graduado na vida profissıonal sub-tema I. In Congresso Brasileiro de Enfermagem XXII, São Paulo, 1970.

18. OLIVEIRA, M. W. R. - Integração do recém-graduado na vida profissional sub-tema III. In Congresso Brasileiro de Enfermagem XXII, São Paulo, 1970.

19. SELLEN \& FURFEY. - Sociology and its uses in nunsing service, $4 .^{a}$ ed., Philadelphia, W. B. Saunders Company, London, 1957.

20. WINGE, S. V. B. - Integração do recém-graduado na vida prifissional, sub-tema II In Congresso Erasileiro de Enfermagem XXII, São Paulo, 1970.

21. WITT, A. - Metodologia de Pesquisa, 1. ${ }^{a}$ ed., São Paulo, Ed. Resenha Tributária, 1973. 
RONCAGLIA, E., colaboradores - Considerações gerais sobre início de carreira, Rev. Bras. Enf., R.J., 28 : 59-68, 1975.

T A B E LA I

Atividades em porcentagem e opção que a enfermeira responsável pela clínica poderia dividir com o recém-graduado no Hospital das Clínicas da FMUSP e Hospital São Paulo, em 1975.

\begin{tabular}{|c|c|c|c|}
\hline Atividades & Sim & Não & Total \\
\hline $\begin{array}{l}\text { Planejamento de cuidado } \\
\text { de enfermagem }\end{array}$ & 96,6 & 3,4 & 100,0 \\
\hline $\begin{array}{l}\text { Orientação aos } \\
\text { funcionários }\end{array}$ & 33,3 & 66,7 & 100,0 \\
\hline Atividades burocráticas & 40,0 & 60,0 & 100,0 \\
\hline $\begin{array}{l}\text { Cuidados a paciente } \\
\text { graves }\end{array}$ & 96,6 & 3,4 & 100,0 \\
\hline
\end{tabular}

FONTE: Formulário Aplicado

\section{ANEXO I \\ FORMULÁRIO ENFERMERO RECÉM-GRADUADO}

Há quanto tempo trabalha?

1 - Você acha que estava preparado para assumir o cargo no seu primeiro emprego?

$\operatorname{sim}$

não

Se a resposta for negativa, por que?

2 - Quais as aptidões que você esperava demonstrar quando começou a trabalhar?

L_ destreza manual

L_ iniciativa

L conhecimentos específicos

—_ segurança no desempenho de suas funçôes

!_ planejamento de cuidados de enfermagem

\_ liderança

L__l Outras

3 - Você teve oportunidade de demonstrar algumas das aptidões relacionadas na questão 2 , no seu emprego atual?

sim

não

Em caso afirmativo, quais? 
RONCAGLIA, E., colaboradores - Considerações gerais sobre início de carreira, Rev. Bras.

Enf., R.J., 28 : 59-68, 1975.

4 - Você esperava ser esclarecido com fundamentação lógica ou científica sobre as atividades que está executando?

$\operatorname{sim}$

$$
\text { não }
$$

5 - Você recebeu estes esclarecimentos?

$\operatorname{sim}$

Partindo do pressuposto que cada profissional fornece informações dentro do seu campo responda:

6 - Você esperava ser orlentado para a atividade que iria desenvolver?

$\operatorname{sim} \mid-1$ não 1

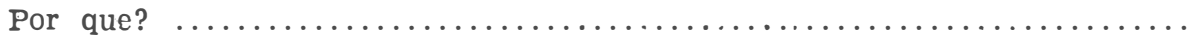

7 - Você recebeu orientação como esperava?

$\operatorname{sim} 1$ năo $\longmapsto 1$

8 - Atualmente você se considera preparado para assumir o cargo que ocupa? sim

não

Em caso afirmativo, por que?

\section{ANEXO II \\ FORMULÁRIO \\ ENFERMEIRA RESPONSÁVEL PELĀ CLININICA}

1 - Que conhecimentos, habilidades e atitudes você espera encontrar no recémformado?

conhecimento científico
destreza manual
atitudes

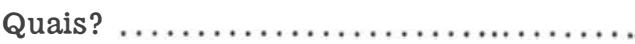

2 - Quando você dá orientação, quais das atitudes abaixo relacionadas você prefere que a pessoa orientada assuma?

— que argumente

—i que receba orientação sem objeções

L que demonstre ter objeções quando as tiver

3 - Quais as atividades educativas você programa e desenvolve para o enfermelro recém-formado?

4 - Por quanto tempo você espera que o enfermeiro recém-formado solicite orientação?

5 - Quais das suas atividades você pod eria dividir com o enfermeíro recém-formado?

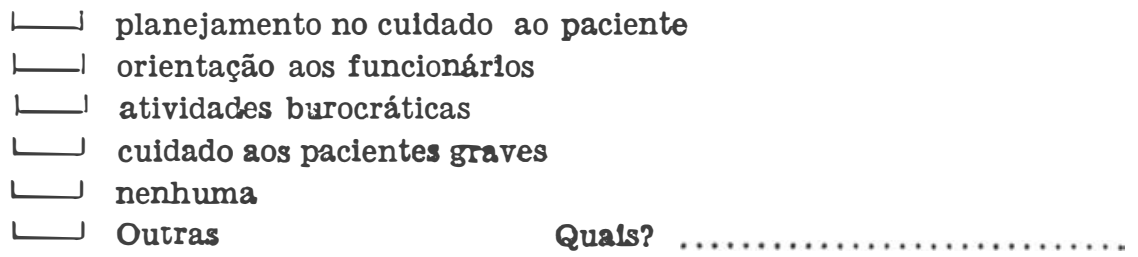

